\title{
Pros and Cons for Teaching Courses in the Classroom and Online Simultaneously
}

\author{
J. Mark Pullen \\ Department of Computer Science and C4I Center \\ George Mason University \\ mpullen@netlab.gmu.edu
}

\begin{abstract}
In adding an online delivery option to an existing graduate program in computer science, important choices include (1) synchronous or asynchronous delivery and (2) for synchronous delivery, whether to deliver classroom and online teaching simultaneously. This paper describes the decisions made in adding an online option to an MSCS program, which now is maturing. The factors in favor of and against simultaneous delivery are discussed in detail and the conclusions reached for one particular program are described, including experience gained in the process and an open-source software system developed to support this form of delivery.
\end{abstract}

\section{Categories and Subject Descriptors}

K.3.1 [Computing Milieux]: Computer Uses in Education distance learning

\section{General Terms}

Management, Performance, Human Factors

\section{Keywords}

Internet distance education, synchronous, asynchronous

\section{INTRODUCTION}

The impact of information technology, and in particular that of the Internet, continues to grow across nearly all domains of teaching and learning. Computer science education is in the vanguard; by the nature of their academic discipline, computer science students and faculty are well prepared to adopt new and experimental approaches including distance education (DE). Our Master of Science in Computer Science (MSCS) program has been offering courses online for over a decade, and has made a full MSCS degree available online since 2004. In the process, we have grappled with issues of effective delivery. This paper reports on our experience and conclusions.

We believe the appropriate question is "How can we best help the student to learn?" Clearly, the answer is highly dependent on the student's learning style and personal situation. We base our approach on two basic premises that have been confirmed by educational research:

1. There is no significant difference in educational outcomes, based purely on mode of delivery. There are differences in costs of teaching and learning and differences in student and faculty

Permission to make digital or hard copies of all or part of this work for personal or classroom use is granted without fee provided that copies are not made or distributed for profit or commercial advantage and that copies bear this notice and the full citation on the first page. To copy otherwise, or republish, to post on servers or to redistribute to lists, requires prior specific permission and/or a fee. ITiCSE'12, July 3-5, 2012, Haifa, Israel. Copyright 2012 ACM 978-1-4503-1246-2/12/07...\$10.00. enjoyment of the educational process, but given the same goals and student motivation the outcomes are the same [16]. This premise is borne out by our own experiences over a five-year period, as shown in Figure 1, taken from [15]. It follows that educational processes should be designed to optimize other factors; generally, economic factors come to the forefront. In our own case, this has taken the form of optimizing time expenditures by the participants. We have found it most productive to minimize time spent by the student commuting to class and time required for the faculty to develop expertise and materials for online teaching.

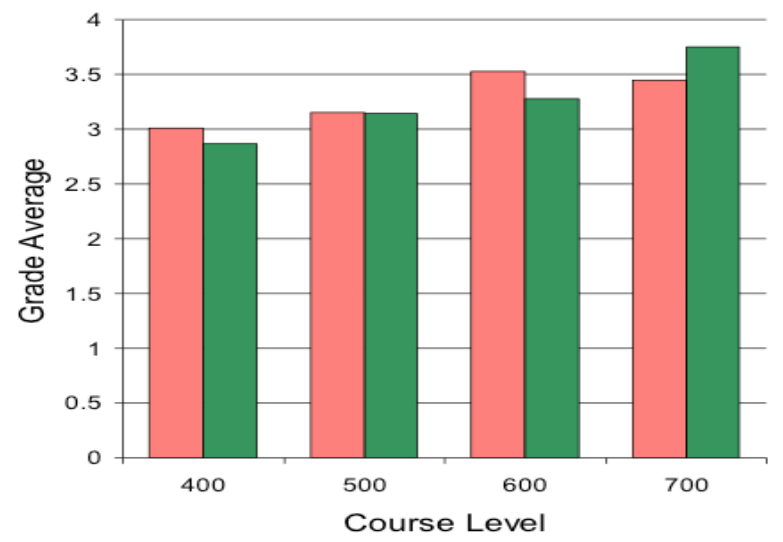

Figure 1. GMU CS grade comparisons (pink: classroom; green: online)

2. Given technologies available today, the most effective way to present material in order to facilitate student learning is a hybrid or blended approach, combining options for classroom learning, online synchronous delivery, and online asynchronous learning materials. This allows students to focus on the form of delivery that best suits their learning style and also allows faculty members to present material in whatever format can convey it most effectively [4,5]. Our approach to this has been to combine classroom delivery with simultaneous online delivery, in a form that maximizes the potential for student/teacher interaction and minimizes impediments presented by the technology, which we call simulteaching. We supplement this combination with asynchronous delivery of both recorded sessions from class and Web-based learning materials and exercises.

This paper is written to explain the choices we have made in adopting the hybrid approach and to review their validity. For this purpose, Section 2 will review the characteristics of synchronous and asynchronous online education; Sections 3 and 4 respectively will examine the pros and cons of the simulteaching approach; Section 5 will illustrate the approach as implemented in our MSCS; and Section 6 will provide an overview of the open source software we have assembled to support it, followed by 
conclusions. While we do not contend that the simultaneous classroom and online delivery mode is the best choice under all circumstances, we believe the discussion below shows that, as a means of expanding regional access to a quality classroom-based program, its benefits considerably outweigh its costs.

\section{SYNCHRONOUS AND ASYNCHRONOUS DELIVERY TECHNOLOGIES}

In this section we consider possible delivery modes for the virtual classroom for topics in engineering and technology, including CS.

\subsection{Synchronous Delivery}

Synchronous means "at the same time" and the synchronous mode is defined essentially by the capability for participants to interact. For many years, the capability was implemented mostly by video teleconferencing. In the past decade, expanded access to goodquality Internet, combined with good multimedia performance in inexpensive computers, has brought Internet delivery to the forefront in synchronous distance education. As a very early adopter [11], our online teaching program originally was confused with "TV teaching" (which is not necessarily interactive) and eventually came to the point of examining whether video is in fact an important medium in teaching computer science and engineering online [12]. We concluded that while video is "nice to have," the decision to provide it is an economic one because few students find video delivery of a "talking head" useful in technical teaching.

It is therefore striking that the general higher education community seems to be experimenting with video delivery today. "Classroom capture" systems [3] have emerged as a new class of teaching technology and many of them feature recording via classroom video cameras (in some cases, multiple cameras). Not all classroom capture offers synchronous delivery, and not all of it focuses on video delivery; however, its emergence as a means of distance education indicates that at least some educators find it attractive. Having concluded that video is not important in online teaching of computer science and engineering, we leave the question of its general applicability to our colleagues in the liberal arts and other academic disciplines.

However, much synchronous online teaching today is not focused on video but rather on good-quality, interactive graphics and Internet voice linked to the World Wide Web (WWW); further, it does not necessarily involve a classroom. Examples of this are Blackboard Collaborate (formerly Elluminate) [2], Adobe Connect [1], and the open-source system described in section 6 below. These systems implement an audiographic channel, with optional video, from the instructor's desktop to that of the online student, and generally support a high level of interactivity if desired by the participants. In fact, each of them has roots in online conferencing technology and can be used for teleconferencing as well as teaching, just as were the video teleconferencing systems originally used for synchronous DE.

\subsection{Asynchronous Delivery}

Asynchronous delivery encompasses the whole range of information conveyance that is not "at the same time" and therefore is much broader. Its original mode was the correspondence course: printed materials, delivered by postal mail or similar techniques, intended for self-study. As recording and multimedia technologies have developed, asynchronous teaching has embraced each in turn. Online and standalone "computer assisted instruction" (CAI) has a rich history of using any sufficiently inexpensive and powerful means of conveying information. The most recent, and arguably the most powerful and flexible, medium to be used for this purpose is the WWW, which can support playback of a wide range of text, audio, and video as well as interactive form that support CAI, as seen in widely-used "learning management system" (LMS) products: commercial Blackboard [2] and open source Moodle [6].

\subsection{Hybrid Modes}

Hybrid modes are possible in different dimensions. Hybridizing in the technology space is natural. Since we know hybrid DE delivery provides the most opportunities to support student learning styles and natural affinities of content to media, it comes as no surprise that the combining the richness of synchronous and asynchronous delivery is a productive approach. The interactive forms of desktop teaching described in the previous paragraph all feature a capability to record synchronous sessions, which results in yet another form of asynchronous delivery, as do the classroom capture systems described above. Both synchronous and asynchronous modes are accessible through a Web-browseraccessed LMS. In addition, many software packages that run on the student's computer are natural parts of today's educational environment. (An example for computer science would be the open source NetBeans Integrated Development Environment for Java [10].) Such software is generally available online; moreover, data associated with student assignments can be made available under an LMS page.

Asynchronous delivery does not necessarily mean that the student is left with complete schedule flexibility. A common experience is that many students lack the self-discipline to maintain a schedule for completion of a course; they tend to postpone required work to the end of the course and then try to complete it in a rush, resulting in a poor learning experience. The syllabus of a traditional classroom course, with its by-date assignments, helps to avoid this problem. This aspect is easily hybridized: create a syllabus with due dates where asynchronous delivery is used. We have students in our MSCS who generally do not attend class in the scheduled time slot, but instead playback the lecture recordings and complete the assignments within the scheduled week. A good way to describe this is "semi-synchronous" DE.

A different dimension of hybridization is the combination of classroom and online synchronous delivery, with students potentially able to move back and forth depending on their personal needs and preferences. This has been part of our MSCS online program from its beginning. (Administratively, we have only a single degree offering, which students access online or in the classroom at their option.) Other programs, both within our own school and across higher education in general, do the same. There are clear benefits associated with this approach, but also there are costs. The next two sections will deal with these pros and cons.

\section{PROS OF SIMULTANEOUS DELIVERY}

This section deals with the many benefits of simultaneous classroom and online course delivery.

\subsection{Low Barriers to Participation}

Most of our faculty members are motivated to provide expanded access to their courses. However, they are busy people who find it difficult to make time to master a new approach to teaching and 
prepare extensive new materials that accompany the approach. With synchronous online teaching, they are in essence continuing to teach as they are accustomed. While it is important to draw the online student into interaction, that is simply an extension of the need to draw the classroom student into interaction. No new materials need be prepared; whatever is used to present the existing course, so long as it is in machine-readable format, will suffice to present the course online. For office hours, simply turn on the delivery software on the office computer and use it to communicate with the student.

\subsection{Good Interaction With All Students}

Good quality Internet synchronous teaching software, such as the three products described in section 2.1, will support spoken and typed communication to and from all participants, including display and annotation of graphic slides. If there is a problem with interaction, it lies in the lack of interest of participants to interact. That is a pedagogical problem, which also happens in the classroom; both in the classroom and online it must be solved by the instructor, not by teaching technology.

\subsection{Reduced Faculty Preparation and Support Time}

Our faculty members are very busy people; most of them already work at least ten hours per day between teaching, research and service; many work even more than this. The prospect of spending extra time developing and maintaining asynchronous course materials and communicating with students by email in place of answering spoken questions is not attractive to them. Synchronous presentation reduces faculty time requirements considerably, with the result that faculty are more willing to teach DE courses. At the same time, our course-end surveys indicate that classroom students find the additional structure associated with DE (posted slides, recordings, LMS webpage, etc.) makes the learning environment more effective for them, as well as for online students.

\subsection{Faculty Salary Savings from Combined Sections}

Our courses have a set maximum number of students that a single instructor is expected to teach. Unless the combined enrollment of classroom and online students exceeds this number, the combined enrollment can be covered in a single presentation. The alternative would be for the instructor to make two separate presentations of the course, at twice the salary cost.

\subsection{More Distance Education Courses}

Most students come to us for a degree program, not just a few courses. Generally, we have enough online students enrolled in introductory graduate courses that a separate online section would fall within the allowable minimum number of students per section. For advanced graduate courses, however, in many cases there are not enough online students to justify a separate section. Offering the course simultaneously to classroom and online student addresses this problem. (In some cases, the combined numbers may be needed to justify classroom delivery also.)

\subsection{Low Support Cost}

Our experience is that, in order for the instructor to pay attention to both online students and classroom students, it is important to support the simultaneous teaching process by having a student assistant monitor the course to make sure all is going well, and be available to assist in case of technology problems (most often issues with sound, such as a dead microphone). However, as the program has ramped up, we discovered that one of these Information Technology Assistants can handle at least three simultaneous classes. The cost of one student assistant is a tiny fraction of the cost of even one faculty member, let alone that of three. The same assistants also maintain the course delivery software on the teaching computers and ensure that all required system functions are working before class. Further, no specialized assistance such as instructional design is required.

\subsection{Enables Flexible Distance Education Delivery}

The recordings of class sessions can be used in various creative ways. For example: Our university offers a very limited number of graduate courses in its summer term. We have addressed the need of students who want to continue their study in the summer by allowing individual students to work with a faculty member who taught an online course and use the recordings originally produced. The students complete all work from the syllabus under which the original course was taught, and are mentored by the instructor who made the recordings. They work on a schedule established by the mentor and must finish within the summer term. To participate, faculty members must be available ten weeks out of the summer by Internet and must have made the recordings in the prior two years. The result enables student progress, provides some extra income for faculty, and leaves all concerned with the feeling that our faculty goes out of its way to help students achieve an education.

This individualized delivery is only an example of the flexibility made possible by capturing classroom activity in recordings. Once an up-to-date set of recordings is available, it is possible to focus on other aspects of learning. The recordings can support an inverted classroom model, where students attend lectures via recordings and spend class time in group or project activities. They also can be shared across faculty teaching the same course, providing students with a variety of teaching styles to facilitate their learning.

\subsection{Expansion of Local Programs}

In recent years, considerable attention has been drawn to asynchronous online programs with global aspirations, such as those of the University of Phoenix [20]. Such programs undoubtedly have a place in higher education; however, so do local programs of excellence. We have chosen not to compete with global online programs. Our DE program is of regional scope, by plan; it requires that students be able to come to campus occasionally for activities such as examinations. Under this arrangement, we are able to serve more students in our metropolitan area, who otherwise would find commuting in rushhour traffic too time consuming, or would not be able to keep up with course requirements due to work schedule and/or travel. 


\section{CONS OF SIMULTANEOUS DELIVERY}

This section deals with the costs associated with simultaneous delivery that are not associated with independent classroom and online delivery.

\subsection{Classroom Equipment Requirements}

The classroom must be equipped with good quality Internet service that is not interrupted during class hours. Also we have found that some device with pen (or finger) input is essential, to support handwritten class material such as that entered on an ordinary classroom whiteboard with no online course. A tablet input device and/or a projected whiteboard such as the commercial SMART Board product [18] fill this need well at a total additional investment less than $\$ 5,000$ per classroom.

\subsection{Administrative Complexity}

Having a different type of classroom for simultaneous online delivery requires that somebody keep track of such rooms and schedule their use. Similarly, having courses that mix online and classroom students means that such distinctions must be conveyed to students. In some cases, DE students pay an extra fee, thus both administrative systems and course delivery software (e.g. the LMS) must keep track of the two groups and provide service accordingly. While this causes extra work for administrative elements, it is financially compensated by extra tuition and also is a source of pride in that the program is serving the needs of more students and serving them better.

\subsection{Faculty Technophobia}

Faculty without good self-confidence in computer technology may be reluctant to take on the additional responsibility of teaching online students in addition to classroom students. This has not proved to be a particular problem in our computer science department, but in other disciplines it might become a more significant issue. We have dealt with this by providing synchronous teaching software with the simplest user interface we could imagine, and also by ensuring that help is available at all times during class as described in section 3.6 above.

\subsection{Technology Problems Can Disrupt Class}

If there is a problem with the computer, software, or network connection, it is possible that the instructor will be distracted in a way that detracts from educating the classroom group. Our experience is that this can be dealt with adequately by providing knowledgeable help on-call to deal with the problem, allowing the instructor to continue working with classroom students. Also any unhappiness on the part of the classroom students can be mitigated by advantages they receive from the simultaneous online delivery, for example: access to class recordings for review or makeup, or the ability to connect online when they must travel for their work.

\section{EXPERIENCE WITH SIMULTANEOUS DELIVERY}

Our university has some characteristics that makes a hybrid classroom/online approach particularly appealing. We are a relatively young institution, in a major urban area. Two situations, common among our students, contribute to their enthusiasm for online course delivery:

- Our urban area is well known for traffic congestion. Our graduate courses are delivered in after-work "rush hour" time, with the result that commuting to and from class can require as much of a student's time as does the class itself.
- Many of our graduate students are employed in government and industry and must travel as part of their work, but can either connect remotely or attend class "time-shifted" via recordings.

Starting with an experimental program carried out by a few "early adopters," we were able to provide enough online courses by 2004 to enable a student to complete the full MSCS degree. Since that time we have added other courses to provide the student with a variety of choices [13]. Table 1 shows the courses currently offered online. Typically we offer six to ten courses online, average classroom attendance was 16.2 students and online attendance was 9.1 students per course from 2006 to 2012. Both classroom and online enrollment has increased over time (19.1 and 15.4 respectively in Spring 2012); the fraction of students enrolled as online is $35.9 \%$ with an upward trend (44.7\% in Spring 2012).

Table 1. Courses Offered in Online MSCS Program

\begin{tabular}{|c|c|}
\hline CS 540 & Language Processors \\
\hline CS 555 & Computer Communications and Networking \\
\hline CS 571 & Operating Systems \\
\hline CS 580 & Introduction to Artificial Intelligence \\
\hline CS 583 & Analysis of Algorithms \\
\hline SWE 619 & Object-Oriented Software Specification and \\
& Construction \\
\hline SWE 620 & Specification \\
\hline SWE 621 & Software Modeling and Architectural Design \\
\hline SWE 625 & Software Project Management \\
\hline CS 640 & Computer Graphics \\
\hline CS 652 & Network Security \\
\hline ISA 656 & Networked Virtual Environments \\
\hline CS 658 & Concurrent Software Systems \\
\hline CS 672 & Advanced Computer Networks \\
\hline CS 706 & Computer System Performance Evaluation \\
\hline CS 755 & Performance Analysis of Computer Networks \\
\hline CS 756
\end{tabular}

All of this was achieved through voluntary participation; by 2009, over half of our department faculty was teaching online. The principal motivation for this was to make our courses more available to students. However, a significant enabler was the low barrier to success: a faculty member who had his or her course materials on machine-readable slides of any form could "go online" after roughly one hour of introduction to online teaching by a colleague. Undoubtedly this played a significant role in expanding course availability.

In supporting the online MSCS, it became apparent to us that every faculty member took an individual approach to online delivery, just as each of them had her or his own approach to classroom teaching. Some of them integrated various software tools into their teaching, while others developed innovative approaches to encourage interaction with online students. In the years when we were using a video camera, one professor developed the practice of turning the camera around to point at the class, based on the conviction that other students would get a better sense of inclusion from that than from seeing her "talking head." Another professor uses handwriting extensively, challenging us to improve the quality of the online whiteboard software. 


\section{OPEN SOURCE SOFTWARE TO SUPPORT SIMULTANEOUS DELIVERY}

Starting in 2004, our C4I Center, which performs research into military information technology and systems, undertook development of an open source software system for online delivery, tailored to the simultaneous classroom and online teaching environment [14, 19]. Our MSCS program used the resulting Network EducationWare (NEW) system until 2010, when we upgraded it.

When we discovered the software integration facilities in the Modular Object-Oriented Dynamic Learning Environment (Moodle), we were motivated to rework our previous efforts into the Moodle environment. Moodle is widely recognized as a highquality Learning Management System (LMS) supporting asynchronous DE [17], with over 66,000 currently active sites registered in 218 countries [7]. Because of its low cost and userfriendly interface, we already were using Moodle as an LMS for course delivery supported by NEW; upon discovering the developer-friendly facilities offered by Moodle [8], we factored Moodle into our development plans. The result was the Moodle Integrated Synchronous Teaching/Conferencing (MIST/C).

MIST/C thus is the result of a decade of building open-source software for simultaneous classroom and online delivery. It features the simplest user interface we have been able to devise, aimed at demanding the least possible attention from the instructor. For example: an audible chime is produced when a student's typed question is displayed, and also when the system raises a popup window that demands the instructor's attention. Also, MIST/C has a feature not available in commercial packages: a separate, fullscreen copy of the whiteboard, used with the classroom projector so that classroom students are not disadvantaged by visual clutter associated with online teaching.

$\mathrm{MIST} / \mathrm{C}$ is described in a nutshell by its hardware requirements (Table 2), functional capabilities (Table 3), and user interface (Figure 2). For more details, see the MIST/C website [9].

\section{CONCLUSIONS}

In our MSCS program, we have demonstrated that there are significant benefits to simultaneous classroom and online delivery. Operational benefits include low barriers to participation, good interaction with all students, requiring reduced faculty preparation and support time, and enabling flexible distance education delivery. Economic benefits include faculty salary savings from combined sections, enabling more distance education courses, low support cost, and enabling expansion of local programs. There are costs associated with these benefits: classroom equipment requirements (most significantly tablet input), increased administrative complexity, dealing with faculty technophobia, and impact of technology problems on classes. However, in our experience these costs are considerably more than offset by the benefits of educating more students and supporting their needs in a more effective way that can save them many hours of commuting (with no educational benefit) each semester.
Table 2. MIST/C Hardware/Software Requirements

Client Operating System: Windows XP/7; MacOS X; Linux Browser: all major

Communication: wired/wireless Internet and dial-up

Security: LDAP authentication

Limitations: seats and classes unlimited

Remote hosting: available at moderate cost

Availability: simple download

Audio: Internet; no separate phone connection needed

Added hardware required: mouse/keyboard/mic; WebCam

Responsiveness: rapid response to user inputs

Table 3. MISTC Functional Requirements

Customizations: accessible/expandable/enhanceable Whiteboard: able to accept graphic files in real time Authoring formats: PowerPoint, PDF, Keynote, OpenOffice

- all participants able to annotate slides during session

Video: common computer formats (mpg, avi, mov); camera

Application sharing: able to export to students the graphic window of any application on the host computer

Recording of sessions: automatic on server; including chat

- able to render as mpeg for podcasting

Interaction: testing; polling/hand-raising; voice + chat

Student tracking: login status; participation statistics

Configurable to screen: by user

Breakout: able to partition class into separate groups

\section{REFERENCES}

[1] Adobe Systems Inc, Adobe Connect and Engaging Webinars, http://www.adobe.com/ConnectWebConference, as of March 2012

[2] Blackboard Inc., Blackboard Collaborate. http://www.blackboard.com/Platforms/Collaborate/Products/ Blackboard-Collaborate.aspx, as of March 2012

[3] Brooks, C., C. Epp, G. Logan and J. Greer, The Who, What, When, and Why of Lecture Capture, Proceedings of the 1st International Conference on Learning Analytics and Knowledge, ACM, 2011

[4] Hrastinski, S. Asynchronous and Synchronous E-Learning, EDUCAUSE Quarterly, 31(4), 2008

[5] Latchman, H., C. Salzmann, D. Gillet and J. Kim, Learning On Demand - A Hybrid Synchronous /Asynchronous Approach, IEEE Transactions on Education 44(2), May 2001 208-225

[6] Moodle, Open-source Community-based Tools for Learning, http://moodle.org, as of March 2012

[7] Moodle, Site Statistics, http://moodle.org/stats, as of March 2012

[8] Moodle, Open Source Software Project Developer Documentation, http://moodle.org/development, as of March 2012

[9] George Mason University Networking and Simulation Laboratory, Moodle Integrated Synchronous Teaching and Conferencing, http://netlab.gmu.edu/MISTC, as of March 2012 
[10] NetBeans, WelcomeTo NetBeans, http://www.netbeans.org, as of March 2012

[11] Pullen, J., The Internet lecture: converging teaching and technology, ACM Special Interest Group on Computer Science Education (SIGCSE) Bulletin Vol 32 No 3 (Sep. 2000), 101-104

[12] Pullen, J., Applicability Of Internet video In distance education For engineering, Proceedings IEEE Frontiers in Education 2001 (Reno, NV, October 2001), T2F-14-T2F-19, online at http://fie.engrng.pitt.edu/ fie2001/papers/1242.pdf

[13] Pullen, J., Scaling up a distance education program in computer science, ACM Special Interest Group on Computer Science Education (SIGCSE) Bulletin 38, 3 (Sep 2006) 33-37

[14] Pullen, J., R. Simon, and P. McAndrews, An Online Graduate Computer Science Program Delivered Via Simulteaching, Advanced Technology for Learning Vol 2 No 3 (Jul. 2005) 148-155, ACTA Press, Calgary, AB

[15] Pullen, J., N. Clark and P. McAndrews, MIST/C: Open Source Software For Hybrid Classroom And Online
Teaching, IASTED International Conference on Technology for Education, Dallas, Texas, December 2011

[16] Russell, T., The No Significant Difference Phenomenon: A Comparative Research Annotated Bibliography on Technology for Distance Education ( $5^{\text {th }}$ ed.), IDECC, 2001

[17] Sclater, N., Large-Scale Open Source E-Learning Systems at the Open University UK, (Research Bulletin, Issue 12). Boulder, CO: EDUCAUSE Center for Applied Research, 2008, available from http://www.educause.edu/ecar

[18] SMART Board, http://smarttech.com/smartboard

[19] Snow, C., J. Pullen, and P. McAndrews (2005), An OpenSource Web-Based System for Synchronous Distance Education, IEEE Transactions on Education 48, 4 (Nov. 2005), 705-712

[20] University of Phoenix, Online College Degree Programs, http://www.phoenix.edu/, as of March 2012

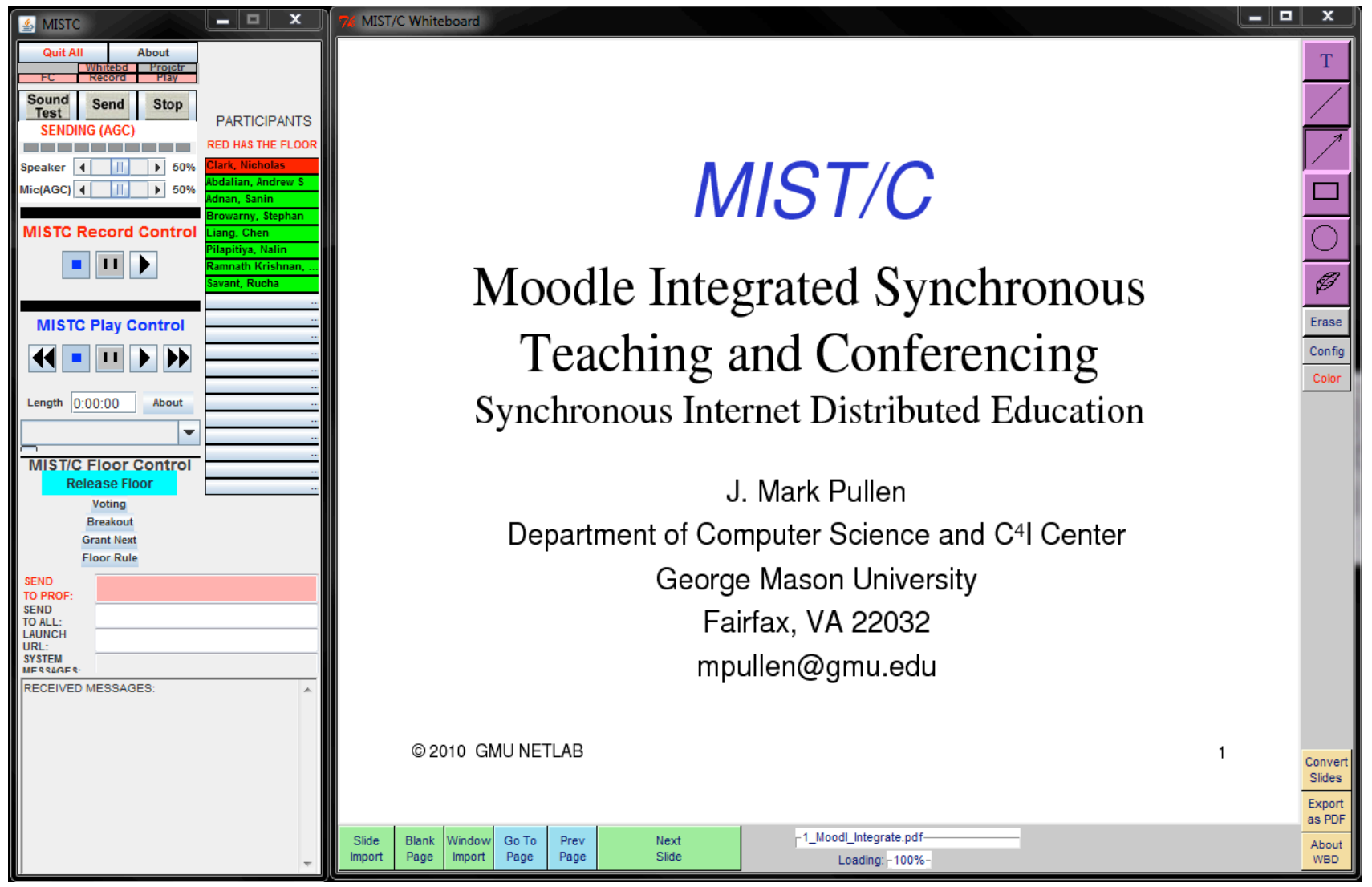

Figure 2. MIST/C User Interface. 